\title{
ПРОУЧВАНЕ НА НАГЛАСАТА НА ГРАЖДАНИТЕ ЗА УПОТРЕБА НА РАСТИТЕЛНИ ХРАНИТЕЛНИ ДОБАВКИ В БЪЛГАРИЯ
}

\author{
Вл. Бачев, И. Янева \\ RESEARCH OF THE CITIZENS' ATTITUDE IN THEIR USE
OF PLANT FOOD SUPPLEMENTS IN BULGARIA
}

Vl. Bachev, I. Yaneva

\begin{abstract}
Рез юм е. Използването на растения за поддържане на здравето е един от най-древните методи в света и у нас. Според резултатите на пилотно проучване относно употребата на растителни продукти (РП) -растителни хранителни добавки (РХД), традиционни растителни лекарствени продукти (ТРЛП), чайове (т.е. воден извлек, получен чрез извличане на студено, чрез варене или запарване на изсушени части от растения или на чели растения) - всички предназначени за употреба без лекарско предписание и наблюдение, българският гражданин не прави разлика между РХД и ТРЛП. Целта на настоящата публикачия е да се проучи нагласата на гражданите относно употребата на РХД. За иелта е проведено срезово анкетно проучване (Cross-sectional survey design) с 400 лица на възраст 18-80 г., изразили желание и съгласие за попьлване на въпросник при гарантирана анонимност. Респондентите са посетили аптека „,Сияна “в гр. София в рамките на 10 дни през 2017 г. Основните изводи от проведеното проучване посочват, че е по-голям относителният дял на респондентите, които не правят разлика между РП и лекарствени продукти (ЛП). Преобладава относителният дял на непотребителите на РП. РХД са предпочитани от малък брой от респондентите (които правят разлика между отделните видове РП) - 5.8\%. Този резултат би могъл да се обясни с предпочитане на традиционния начин на употреба на РП у нас - под формата на чай. Най-употребяваното растение под форма на РХД е валерианата. Според 43.5\% от респондентите, РХД са безопасни. Данните от извършеното проучване посочват, че у нас съществуват проблеми при употреба на РП за здравни иели, които се купуват без лекарско предписание и наблюдение.
\end{abstract}

S u $\boldsymbol{m} \boldsymbol{m}$ u ry. Plant usage for supporting of health is one of the most ancient methods in the world and in our country. Preliminary pilot research at home shows that Bulgarian citizen in most cases does not separate among the different types of plant products ((traditional plant medicinal products (TPMP), plant food supplements (PFS), teas)). The aim of current publication is to research the attitude of citizens about plant food supplements, which are intended to purchase without them being subject to prescription and medical observation. A study was conducted (Cross-sectional survey design) with 400 people, aged 18-80 years in 2017, who expressed willingness and agreed to fill a questionnaire with a guaranteed anonymity. They have been in "Siyana" Pharmacy, city of Sofia, within 10 days. The main conclusions that can be drawn in general from conducted research are that the relative share of respondents who do not distinguish between plant and medicinal products is higher. Overall, from the representative sample is predominant the relative share of non-users of plant products. PFS are preferred by a small number of respondents who make a distinction between different types of the plant products $-5.8 \%$. This result can be explained by the preference of the traditional form of use of the plant products in Bulgaria - a tea. The most commonly used plant in our country in the PFS is the Valeriana officinalis L. According to 40\% of respodents the PFS is safe. The recorded information from conducted research shows that in our country exist problems in usage of plant products for health purposes, which can be bought over the counter without doctor's prescription and observation.

Key words: attitude of citizens, usage, plant food supplements, Bulgarian citizens

\section{Въведение}

Използването на растения за поддържане на здравето е един от най-древните методи в света и у нас [8]. Растенията по литературни данни се използват за здравни и диетични цели под формата на чайове, сокове, растителни лекарствени продукти, растителни хранителни продукти (РХД) [11, 12, 13] - храни, чиято цел е да допълват нормалната диета, които съдържат растения, части и екстракти от растения. РХД се предлагат под формата на капсули, таблетки, хапчета и други като сашета на прах, ампули с течности, капки и други подобни форми, предназначени за приемане в дозирани малки единични количества [1], които за разлика от ТРЛП, според законодателството в тази област, не могат да имат претенциите, че се използват за лечение и профилактика на болестите. На този етап във всяка страна на Европейския съюз се прилагат национални правила, които засягат РХД. За хранителните добавки (ХД) режимът е уведомителен. Уведомлението за пускане на пазара на ХД у нас се подава в Българската агенция по безопасност на храните, като към него се прилага образец на етикета на ХД (опаковка, листовка, брошура - при наличие на такива). Националните изисквания у нас относно РХД включват „негативен списък“ от 120 растителни видове и родове, забранени за влагане в състава на ХД, [8], за разлика от препоръчителния „негативен“ списьк на Компендиума на
Европейския орган по безопасност за храните, който наброява над 900 растителни видове и родове [10]. В РХД се влагат растения, съдържащи биологично активни вещества, които оказват фармакологични ефекти. Поради този факт претенцията в нормативните документи [4], засягащи РХД (че ХД не могат да се свързват с „лечение и профилактика на болести“) е нелогична. За разлика от РХД, традиционните растителни лекарствени продукти (ТРЛП) са лекарствени продукти, съдържащи растения, които се използват за профилактика и лечение на заболявания и според състава и целта за употреба са предназначени за употреба без лекарско предписание и наблюдение, регистрират се по облекчена процедура съгласно Закона за лекарствените продукти в хуманната медицина. Те са ЛП и според Закона за лекарствените продукти в хуманната медицина [3] и са представени като притежаващи свойства за лечение или профилактика на заболявания при хора [3]. Общото между РЛХД и ТРЛП е, че са предназначени за употреба без лекарско предписание и наблюдение. В някои Европейски страни по отношение на ХД режимът не е толкова либерален, колкото у нас, което е в интерес на безопасността на пациентите [2, 12].

Целта на настоящата публикация е да се проучи нагласата на гражданите относно употребата на РХД, които са предназначени за закупуване без лекарско предписание и наблюдение. 
Дизайн на проучването. Проведено е срезово анкетно проучване (Cross-sectional survey design) с 400 лица на възраст 18-80 г., които са посетили аптека „Сияна“ в гр. София в рамките на 10 дни през 2017 г. и всички са се отзовали да попълнят анонимно, разработен за целта, въпросник.

\section{Методи}

А. Социологически метод - пряка индивидуална анкета, попълнена анонимно от отзовалите се респонденти.

Б. Документален метод - анализ на данни от: литературни източници - монографии, научни публикации, интернет и др.

В. Статистическият анализ на данните от анкетните карти е извършен чрез статистическия пакет SPSS 20.0. Използван е метод за проверка на хипотези - хи квадрат $\chi^{2}$ (Fisher's Exact Test). Съответната нулева хипотеза се отхвърля, когато стойността на гаранционната вероятност е $\mathrm{p}<0.05$. София

Ограничение - проучването е проведено само в град

\section{Резултати и дискусия}

Социално-демографски характеристики на респондентите - възраст, пол, образование, трудова заетост

В проучването са участвали 400 лица от град София. От тях 181 (45.3\%) са мъже, жените са 219 (45.3\%). Респондените са на възраст между 18 и 80 години. Средната им възраст е 45 г. \pm 13 , а най-често срещаната възраст сред участниците са 39 и 42 години (6.3\%). За целите на изследването респондентите са групирани в две възрастови групи: 18-39 г.; 40-40+ години (40-80 г.). Преобладава относителният дял на лицата във възрастовата група 40-40+ г. - 64.2\%. Относителният дял на групата 18-39 г. е 35.8\%, Преобладава относителният дял на респондентите със средно образование - 40\%. Преобладаващ дял в извадката са респондентите, които живеят в семейство или съжителство $-63.5 \%$. Найголям е относителният дял на респондентите „служители на умствен труд“ $-59.75 \%$. Преобладаващ е относителният дял на респондентите, които са на „недържавна служба“ $45 \%$, следвани от тези на държавна служба $-21.75 \%$, което може да се обясни с ограничаващия фактор, че всички респонденти са от град София. Това предполага, че по-голямата част от тях работят и са на „недържавна служба“, или на “държавна служба“.

\section{Нагласа на гражданите за употребата на РХД}

Преобладават относителните дялове на мъжете и жените респонденти, които не правят разлика между растителни продукти (РП) и лекарствени продукти (ЛП). Тези относителни дялове са близки по стойност до относителния дял на респондентите, които са приемали РП - 12.5\%. Преобладава относителният дял на жените респонденти с висше образование, които предпочитат РП пред ЛП - 17.9\%. Това донякъде потвърждава резултатите от проучвания, които гласят, че потребителите на ХД, включват лица с висока степен на образование $[9,16]$. Относителният дял на респондентите, които не правят разлика между РХД, ТРЛП и чай е висок $-89.4 \%$. Това би могло донякъде да се обясни с неползването на различни канали за здравна комуникация [5, $6,7] .93 \%$ от респондентите, които правят разлика между отделните видове РП са отговорили, че биха предпочели формата - чай, следва групата на тези, които биха предпочели РХД $-5.8 \%$. В потвърждение на тези резултати, най-голям е относителният дял на респондентите, които приемат РП и биха ги предпочели под формата на чай $-76.55 \%$, следвани от групата на респондентите, които предпочитат РХД, с от- носителен дял 5.5\%. Получените резултати у нас са близки до тези на Европейско проучване на проект Plantlibra [11], според което дельт на непотребителите на ХД във Обединеното кралство и Италия преобладава над този на потребителите. Преобладаващият относителен дял на респондентите, предпочитащи РП под формата на чай, би могъл да се обясни с традиционния начин на употреба на растенията у нас. От респондентите, които са употребявали РХД, във възрастовата група 18-39 г. преобладава относителният дял на жените респонденти - 69.5\% (наблюдавано и при други проучвания $[12,13,14])$, а във възрастовата група 40-40+ найвисок е относителният дял на мъжете респонденти $-70.8 \%$. Общо в двете възрастови групи относителните дялове на респондентите: мъже $-67.4 \%$ и жени $-66.7 \%$, употребявали РХД, са приблизително равни, Фигура 1.

Фигура 1. Разпределение на респондентите по пол и възрастови групи относно употребата на ХД

Ако сте употребявали/употребявате ХД от какъв произход са те?

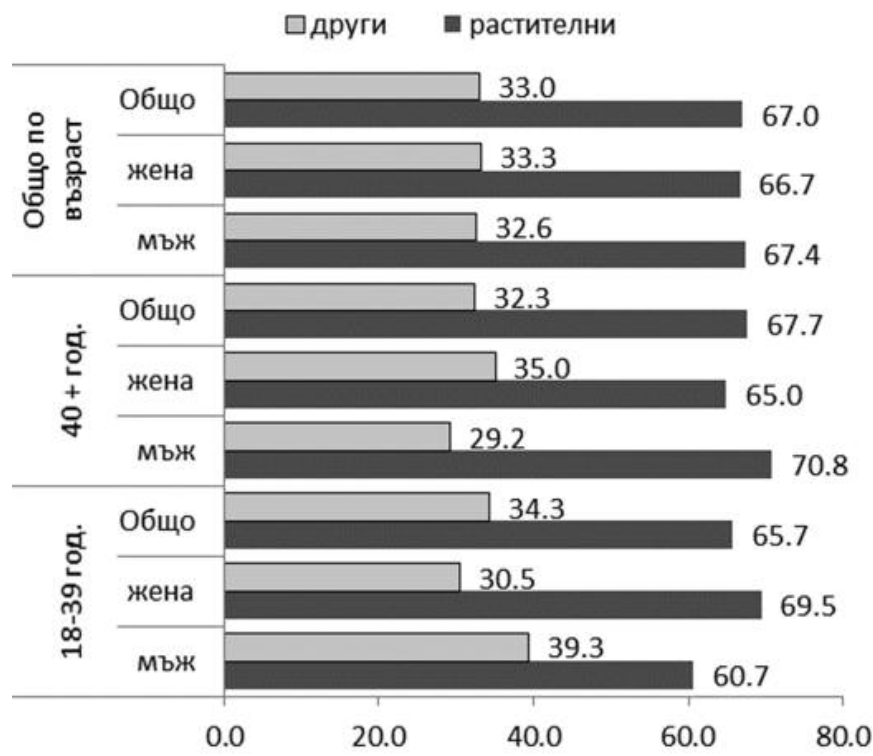

Най-висок е относителният дял на групата респонденти ,„разделен/а или разведен/а“ $-49.1 \%$, които предпочитат да приемат РХД, $\mathrm{p}<0.05$. Този резултат би могъл да се обясни с всеобщото мнение, че РХД са по-евтини от ЛП и се закупуват от тази група, поради социалния ѝ статус (предполага ce, че тази група е с по-ниски доходи, отколкото групата на респондентите, живеещи в съжителство). Най-голям е относителният дял на респондентите, които са употребявали РХД в продължение на 1 месец $-74.5 \%$.

Респондентите, които са употребявали РХД, са посочили следните 10 най-употребявани от тях растения през 2016 г., подредени в низходящ ред - валериана (Valeriana officinalis L.), лайка (Matricaria chamomilla L.), гинкго билоба Ginkgo biloba L.), липа (Tilia), жълт кантарион (Нypericum perforatum L.), черен бъз (Sambucus nigra L.), мащерка (Thymus serpyllum L.), мечо грозде (Arctostaphylos uva-ursi L.), шипка (Rosa canina L.), лавандула (Lavandula angustifolia Mill.). B потребителското проучване на Проект PlantLibra, (Usage of Plant Food Supplements across Six European Countries: Findings from the PlantLIBRA Consumer Survey, [11]), проведено във Финландия, Германия, Италия, Румъния, Испания и Обединеното кралство [11] са определени 11, най-често използвани растения в състава на РХД в тези страни - гинкго билоба, вечерна иглика, артишок, жен шен, алое вера, копър, валериана, соя, маточина, ехинацея, черна боровинка. В отделните страни се наблюдават различия по отношение на подреж- 
дането на отделните растителни видове. Резултатите от настоящето проучване, сравнени с тези от проучване на Проект PlantLibra [11], посочват общи тенденции. Така например валерианата (Valeriana officinalis L.) и гинкго билоба (Ginkgo biloba L.) са сред най-често използваните растения под формата на РХД. Буди безпокойство фактът, че в литературата се съобщават данни за възникване на нежелани лекарствени реакции при едновременна употреба на гинкго билоба (Ginkgo biloba L.) и валериана (Valeriana officinalis L.) с други ЛП [14]. Всички тези факти говорят за едно - дори и РП, които са предназначени за закупуване без лекарско предписание и наблюдение, трябва да се приемат след консултация с лекар-специалист. Според $43.5 \%$ от респондентите, които правят разлика между РХД и ЛП, РХД са безопасни, като относителният дял на мъжете респонденти (45.3\%) преобладава над този на жените $-42 \%$. Най-висок е относителният дял на групата респонденти със средно образование, които смятат, че РХД са безопасни $-46.9 \%, \mathrm{p}<0.05$. Респондентите, които са решили да си купят РП, преди да се лекуват с ЛП, са посочили различни поводи. Най-висок е относителният дял на респондентите, които са отговорили, че „растенията са безвредни“ - 86.8\%, следва групата на респондентите, които ,не вярват на методите на официалната медицина 12.3. $79.6 \%$ от респондентите не са срещнали трудности при търсене на определен РП.

В заключение може да се посочи, че у нас преобладават непотребителите на РП. Този резултат потвърждава други резултати от проучването, според които преобладават относителните дялове на респондентите, които не правят разлика както между РП и ЛП, така и между отделните видове РП. РХД са предпочитани от мальк брой от респондентите - относителен дял 5,8\%, което би могло да се обяснени с традиционния начин на употреба на растения у нас, а именно - под формата на чай [8]. Най-употребяваното растение у нас под форма на РХД е валерианата, която е посочена сред най-често употребявани растения под форма на РХД и от потребители в други Европейски страни. Необходимо е създаване на цялостна база данни за РП, която да съдържа надеждна информация за отделните растителни видове по отношение на фитохимичен състав, фармакологична активност, нежелани лекарствени реакции, нежелани лекарствени взаимодействия, токсичност, противопоказания и пр., за да се гарантира безопасността на гражданите, потребители на различни РП.

\section{Библиография}

1. Архив на В.Бачев

2. Бачев, В., И.Янева. Сравняване на българското и европейското законодателства в областта на растителните хранителни добавки, БСОЗ, 2018, том 10, кн.1, 53-66. (in Bulgarian)

3. Закон за лекарствените продукти в хуманната медицина, в сила от 13.04.2007 г., Обн. ДВ. бр. $31 / 2007$ г., изм. и доп. ДВ. бр.48/2015 г.

4. Наредба № 47 ОТ 28 декември 2004 г. За изискванията към хранителните добавки. В сила от 01.08.2005 г. Издадена от МЗ. Обн. ДВ. бр.5 от 14 Януари 2005г., изм. ДВ. бр.90 от 11 Ноември 2005 г.,
бр.44 от 5 Юни 2007 г., изм. ДВ. бр. 90 от 16 Ноември 2010 г.

5. Каранешева, Т., Изборьт на комуникационен канал - фактор за ефективна здравна комуникация, Българско списание за обществено здраве, 2015, 7(3):35-47.

6. Каранешева, Т., Потенциальт на интернет като канал за здравна комуникация, Социална медицина, 2016, кн.1: 30-33

7. Каранешва, Т., Н. Данова, Предпочитани канали за здравна комуникация сред население на възраст 20-39 години, Българско списание за обществено здраве, 2016, 8(3):23-31.

8. Материали за български ботанически речник. (1939) Събрани от Б. Давидов и А. Явашев, подредени от М. Шосев и П. Балабанов, доп. и ред. от Б. Ахтаров, София, Придворна печатница, $575 \mathrm{ctp}$.

9. Block G, Jensen CD, Norkus EP, Dalvi TB, Wong LG, McManus JF, Hudes ML. (2007) Usage Patterns, Health, and Nutritional Status of LongTerm Multiple Dietary Supplement Users: a Cross-Sectional Study, Nutr J, 6: 30. https://www.ncbi.nlm.nih.gov/pmc/articles/PMC2164946/

10. European Food Safety Authority (2012) Compendium of botanicals reported to contain naturally occurring substances of possible concern for human health when used in food and food supplements. EFSA Journal 10(5): 2663. [60 pp.] doi:10.2903/j.efsa.2012.2663, www.efsa.europa.eu/efsajournal. Accessed 2013 September 15.

11. Garcia-Alvarez, A., Egan, B., De Klein, S., Dima L., Maggi F. , Isoniemi, M., Ribas-Barba, L., Raats, M., Meissner, E., Badea, M., Bruno, F., et all. (2014) Usage of Plant Food Supplements across Six European Countries: Findings from the PlantLIBRA Consumer Survey, PLoS One, 9(3): e92265. Published online 2014 Mar 18. doi: 10.1371/journal.pone.0092265, www.ncbi.nlm.nih.gov/ pmc/articles/PMC3958487/

12. Larrañaga-Guetaria, A. (2012) PlantLIBRA: PLANT food supplements, levels of Intake, Benefit and Risk Assessment. The regulatory framework for plant food supplements in the EU, AgroFOOD industry hi-tech, 23(5): 20-22.

13. Menniti-Ippolito, F., Gargiulo, L., Bologn,a E., Forcella, E., Raschetti, R. (2002) Use of unconventional medicine in Italy: a nation-wide survey, Eur J Clin Pharmacol, 58: 61-64.

14. Messerer, M., Johansson, S.E., Wolk, A. (2001) Use of dietary supplements and natural remedies increased dramatically during the 1990s, J Intern Med, 250: 160-166.

15. Milić, N., Milosević, N., Golocorbin Kon, S., Bozić, T., Abenavoli, L. Borrelli, F. (2014) Warfarin Interactions With Medicinal Herbs, Nat Prod Commun, 9(8): 1211-6.

16. Rock, C.L. (2007) Multivitamin-multimineral supplements: who uses them? Am J Clin Nutr, 85(1): 277S-279S.

17. Steg P., James S., Atar D., Badano L., Blömstrom-Lundqvist C., et all. (2012) ESC Guidelines for the management of acute myocardial infarction in patients presenting with ST-segment elevation. Task Force on the management of ST-segment elevation acute myocardial infarction of the European Society of Cardiology (ESC), Eur. Heart J, 33(20): 2569-619.

18. Schaffer, D.M., Gordon, N.P., Jensen, C.D., Avins, A.L. (2003) Nonvitamin, Nonmineral Supplement Use Over a 12-month Period by Adult Members of a Large Health Maintenance Organization, J Am Diet Assoc, 103 (11): $1500-1505$.

\section{Автор}

Владислав Бачев, магистър-фрармацевт; Илияна Янева, доцент, Национален център по обществено здраве и анализи

Че робството, сиромашията, несигурността, постоянните теглила са били един от факторите за подтикване на хората по него време към пиянство, личи от стихотворението „Пиеница“, написано от Стефан Стамболов. Ето какво четем в него:

\section{Защ, да ви приказвам / за наште теглила? Трябва ли да разбутвам / на мъртвите съня? Захванах да заливам / с вино мойта скрвб. И в него да намирам / утеха в този свят.}

...Възрожденската медицинска книжнина е резултат на общия труд на много наши млади възрожденски лекари, учители и други книжовници.
Най-изтькнати автори и преводачи на медицински книги и други печатни материали са лекарите: Иван Богоров (1818-1892) от Карлово, Венко Н. Гръмников (18461874) от Ст. Загора, Димитър Моллов (1845-1914) от с. Беброво, Еленско, Димитър Начев от Болград, Начо Планински (1847-1895) от Ст. Загора, Петър Д. Протич (1822$1881)$ от Търново, Христо Стамболски (1843-1932) от Казанлък, Тодор Ив. Стоянович (1844-1894) от Ст. Загора, Георги К. Хаканов (1851-1898) от Казанльк, Стоян Ив. Чомаков (1819-1893) от Копривщица, Васил Костов Караконовски (1840-1905) от Ловеч и др.

\section{д-р Христо Големанов, „Възрожденската} медииинска книжнина", Медицина и физкултура, 1964 